\title{
Low emotional arousal in depression as explained by the motivated attention approach
}

\section{La baja activación emocional en la depresión explicada por el enfoque de la atención motivada}

\author{
Stephan Moratti, PhD \\ Departamento de Psicología Básica I. Universidad Complutense de Madrid, España. \\ Centro de Tecnología Biomédica, Universidad Politécnica de Madrid, España.
}

Disponible online 31 de agosto de 2012

\begin{abstract}
Depression has been associated with low emotional arousal. Highly arousing emotional stimuli engage the cortical circuits related to the allocation of attention towards these stimuli. Thus, it has been hypothesized that depression could be characterized by a deficit in these brain circuits. This brief review summarizes how attention and emotion are interconnected and suggests that common brain mechanisms underlie the link between emotion and attention. Finally, the results from depression research are presented that show that low emotional arousal in depression could arise from a deficit in brain circuits related to attention.
\end{abstract}

Keywords: Depression; Emotion; Attention; Fronto-parietal cortex.

La depresión se ha asociado con baja activación emocional. Los estímulos emocionales de alta activación involucran circuitos corticales que son relevantes para la dirección de la atención hacia estos estímulos. Por lo tanto, se ha planteado la hipótesis de que la depresión podría ser caracterizada por un déficit en estos circuitos cerebrales. Esta breve revisión resume como la atención y la emoción están interrelacionados y sugiere que existen mecanismos cerebrales de la emoción y la atención comunes. Por último, se presentan los resultados de una investigación de la depresión, que demuestra que la excitación emocional baja en la depresión podría surgir de un déficit en los circuitos cerebrales de la atención.

Palabras Clave: Depresión; Emoción; Atención; Corteza fronto-parietal.

Correspondence concerning this article should be addressed to: Stephan Moratti, Universidad Complutense de Madrid, Departamento de Psicología Básica I, 28223 Pozuelo de Alarcón (Madrid), España. E-mail: smoratti@psi.ucm.es

This brief review has been motivated by a talk given at the "II Jornada de Neurociencia Afectiva: Avances en el estudio de la depresión", 2011 in Malaga, Spain. 
One of the main characteristics of depression is disturbed processing of emotional information as indexed by disturbed startle reflex modulation during emotional stimuli and facial expression (Forbes, Miller, Cohn, Fox \& Kovacs, 2005; Gehricke \& Shapiro, 2000). Low engagement of arousal related brain structures during emotional information processing has been associated with anhedonia and blunted affect in depressive disorders (Heller \& Nitschke, 1997). In healthy persons automatic attention allocation towards emotional high arousing stimuli like emotional pictures or words has been associated with motivated attention (Bradley, 2009; Lang, Bradley \& Cuthbert, 1997). Motivated attention is a concept that has been introduced by researchers which have emphasized that high arousing stimuli, motivationally relevant for the individual, engage orienting responses (Bradley, 2009). These responses are reflected in (1) behavioral measures of attention (Öhman, Flykt, \& Esteves, 2001), (2) changes of autonomous nervous system activity such as heart rate deceleration or skin conductance increases (Bradley, Codispoti, Cuthbert \& Lang, 2001), and (3) central nervous activity in attention related brain structures (Moratti, Keil \& Stolarova, 2004; Moratti, Saugar \& Strange, 2011). This line of research has a long tradition and the processes involved are well studied although some issues are still under debate. Therefore, the motivated attention approach offers a profound framework for studying pathologies associated with emotion processing disturbances such as depression. In the present brief overview we first present some basic foundations of the motivated attention approach and related brain structures and second present results that associate depression with deficits in attention relevant brain structures.

\section{Attention and emotion}

The orienting response (OR) is associated with the automatic detection of novel stimuli in our environment because novel stimuli bear significance for the reorganization of the organism's ongoing behavior. As our capacity of stimulus processing is limited and the environment is full of many stimuli, we have to filter somehow the important environmental cues. Attention allocation during an OR towards a specific stimulus serves this function. The attention processes related to the OR have been associated with physiological arousal. A classical measure of the OR is the sympathetically mediated skin conductance response (Critchley, 2002). Skin conductance increases for novel stimuli (Venables \& Cristie, 1980). However, a stimulus can have a motivationally important significance not only for its novelty. An emotional stimulus bears motivational significance for the individual as well (for example a dangerous or pleasant stimuli associated with food or sex). Thus, if high arousing emotional stimuli capture attention automatically, they should provoke similar physiologic responses as can be observed during an OR. Bradley, Lang \& Cuthbert (1993), observed that pleasant and unpleasant pictures provoke increased skin conductance responses compared to neutral images. However, when presented for the first time, neutral stimuli also provoked skin conductance changes different from zero. Nevertheless, when the same pictures were shown to the same participants one week later, only emotional pictures elicited increased physiological arousal.

Attention allocation towards emotional high arousing stimuli can be also observed on the behavioral level. When participants have to detect fear relevant stimuli such as snakes or spiders within many fear irrelevant distractors, they are much faster than vice versa (Öhman et al., 2001). This effect is augmented when subjects suffer from phobias of snakes or spiders indicating that increasing the motivational relevance of the stimuli boosts automatic attention allocation. Thus, it can be concluded that emotion drives natural selective attention (Öhman et al., 2001).

Another strategy to link attention and emotion with respect to brain responses is to compare the cortical processing of stimuli that do not bear any emotional significance but have to be attended with the cortical processing of emotional stimuli. If similar effects can be observed one can infer that the brain is using at least partly overlapping brain mechanism for emotion and attention. For example it has been shown that neurons discharge preferentially for different objects within the ventromedial temporal cortex in monkeys (Chelazzi, Duncan, Miller \& Desimone, 1998). However, increased neuronal firing rates for a preferred object can only be observed over a longer time period if the monkey directs its attention to that object (Chelazzi et al., 1998). Thus, cortical processing within specialized brain regions that code specific objects is enhanced when the corresponding objects are attended. Humans and monkeys also have specialized brain areas (in humans fusiform face area; FFA) for face processing (Kanwisher \& Yovel, 2006; Sugase, Yamane, Ueno \& Kawano, 1999). In monkeys, neuronal firing rates in temporal cortex are increased and prolonged when the facial expression is emotional (Sugase et al., 1999). In humans, hemodynamic responses are increased in the FFA when emotional faces are shown (Vuilleumier, Armony, Driver \& Dolan, 2001). Neutral meaningless gray gratings without any significance for the individual provoke increased activity in occipital cortex after having been paired with an aversive loud noise (Moratti \& Keil, 2009). The enhanced visual processing after learning occurs independently of conscious expectancy of the aversive stimuli (Moratti \& Keil, 2009). Angry prosody of meaningless speech stimuli results in augmented activity in primary auditory cortex (Grandjean et al., 2005). Thus, emotionally relevant stimuli elicit increased neural activity in its corresponding primary cortices the same way as attended stimuli do.

Thus, it is tempting to assume that attention and emotion utilize the same mechanism to achieve enhanced stimulus processing in involved brain regions. If so, emotion and attention should have an additive effect with respect of neural activity. The emotional facilitation of the hemodynamic response in 
FFA is enhanced when participants have to attend to the emotional face explicitly (Vuilleumier et al., 2001). Activity in primary auditory cortex for attended vs. non-attended meaningless speech that is spoken with an angry prosody is enhanced (Grandjean et al., 2005). The emotional modulation of EEG (electroencephalogram) responses at occipital electrode sites is also amplified by attention (Keil, Moratti, Sabatinelli, Bradley \& Lang, 2005). Therefore, it is likely that similar brain mechanisms underlie attention and emotion related sensory facilitation.

But how is the facilitation of emotional stimulus processing in sensory cortex accomplished? It is widely accepted, that direct projections from the amygdala to primary sensory cortex can be responsible for fast enhanced sensory processing of emotional stimuli (Amaral, 1986; Amaral, Price, Pitkaenen an Carmichael, 1992). The amygdala has been considered a core structure for fear learning and the detection of motivationally relevant stimuli (LeDoux, 2000). The so-called "fast and direct route" of emotion explains why fear relevant stimuli can be processed very fast at early sensory stages (Keil, Stolarova, Moratti \& Ray, 2007). However, emotional stimuli can provoke affective responses even without perceptual consciousness (Ohman, Carlsson, Lundqvist \& Ingvar, 2007) as affective information is conveyed directly from the thalamus to the amygdala (Shi \& Davis, 2001). The amygdala can evoke emotion related responses via its efferents to response related structures (hypothalamus; periaqueductal gray; (LeDoux, 1993)) without any cortical processing of the stimuli. Therefore, sustained late onset top down influences on primary sensory cortices during emotional processing probably have a different origin. With respect to the above mentioned attention related effects it is more probable that other structures than the amygdala play a modulatory role in late long lasting facilitating sensory processing.

Several studies have shown that directing attention towards a stimulus in space or towards a certain feature of a stimulus (such as color or shape) implicate a fronto-parietal cortical network (for example Slagter et al., 2007). Therefore, we can speak of a general fronto-parietal attention circuit in the brain. Further, clinical studies in humans have shown that parietal and frontal brain damage leads to a condition called spatial neglect that is a pathology associated with deficits of spatial attention (Driver \& Vuilleumier, 2001).

If motivationally relevant cues attract attention, so that they will be preferentially processed in comparison to all other stimuli, it is plausible that a fronto-parietal cortical attention system comes into play during attention allocation towards these cues. Evoked steady state responses are oscillatory EEG/ MEG (magnetoencephalogram) responses that are driven by the frequency of a stimulus flicker (Moratti, Clementz, Gao, Ortiz \& Keil, 2007). Usually the flicker is presented for several seconds and the brain oscillatory steady state response represents cortical processing of the flicker over that time period. Thus, evoked steady state responses are ideally suited to investigate stimulus related dynamic brain processes over several seconds. It has been consistently shown that spatial or feature based attention modulates the steady state response. Attended stimuli evoke greater stimulus driven oscillations than non-attended cues (Morgan, Hansen \& Hillyard, 1996; Müller et al., 2006; Müller \& Hillyard, 2000; Müller \& Hubner, 2002). Using emotional pictures from the International Affective Picture System (IAPS, (Lang, Bradley \& Cuthbert, 2005)) as flickers, Moratti and collaborators (Moratti et al., 2004) have shown that visual evoked steady state responses are greater for emotional pictures than for neutral ones. Using cortical source localization, the emotion modulation of the brain oscillatory response could be localized within occipital and fronto-parietal brain sources. This indicates the involvement of a fronto-parietal attention circuit during emotional picture processing (Moratti, et al., 2004).

However, probably one of the most consistent ERP (event related potentials) results with respect to emotion is the affect modulation of the Late Positive Potential (LPP). The LPP is a slow going ERP potential that begins approximately $400 \mathrm{~ms}$ after stimulus onset and has bigger amplitudes for emotional pictures (Codispoti, Ferrari \& Bradley, 2006; Cuthbert, Schupp, Bradley, Birbaumer \& Lang, 2000; Hajcak, Dunning \& Foti, 2009; Schupp, et al., 2000). The LPP has been associated with attention allocation towards motivationally significant stimuli such as high arousing pleasant and unpleasant pictures (Cuthbert, et al., 2000). However, the underlying source structure and cortical network characteristic has been unknown so far. A recent MEG study (Moratti, et al., 2011) using modern beamformer techniques for cortical source localization revealed that the LPP emotion modulation occurs in fronto-parietal brain areas. Further, frontal and parietal brain areas were coupled bidirectionally demonstrating that these regions formed a functional cortical network.

In sum, emotion enhances neuronal processing of stimuli just as attention does. Further, sustained attention allocation processes towards emotional stimuli are probably accompanied by the involvement of cortical fronto-parietal attention circuits. The concept of motivated attention therefore captures very well how attention and emotion are interwoven.

\section{Cortical attention circuits and depression}

The concept of motivated attention not only emphasizes attention per se, but also implies that emotional stimuli activate appetitive or defensive motive systems (valence), which in turn activate action dispositions according to their corresponding hedonic valence. The intensity of the activation of one of the motive system is referred to as emotional arousal (Lang \& Davis, 2006). High arousing emotional stimuli guide attention allocation towards significant environmental cues; for example as reflected by an OR (Bradley, 2009).

Based on neuropsychological, electrocortical, and behavioral measures of lateralized brain activation, Wendy Heller 
and collaborators (Heller, Nitschke \& Lindsay, 1997; Heller, Nitschke \& Miller, 1998) proposed that action tendencies reflecting positive and negative valence (approach vs. withdrawal), engage the left and right frontal cortex, respectively. In contrast, emotional arousal is based on right temporo-parietal cortex function. Note that as elaborated above, the right parietal cortex forms part of the fronto-parietal cortical attention circuit and that high emotional arousing stimuli attract attention.

Therefore, automatic attention allocation by emotional stimuli such as the OR should be impaired in patients with lesions within the cortical attention system. Meadows and Kaplan (1994), observed that patients with right parietal lesions showed reduced skin conductance in comparison with healthy controls when viewing emotional slides indicating less physiological arousal and reduced ORs in these patients. Further, patients with right posterior brain lesions are more likely to develop depression (Shimoda \& Robinson, 1999). Depression has been associated with low emotional arousal (Heller $\&$ Nitschke, 1997). Therefore, it is probable that reduced emotional arousal and impaired right parietal cortex function are somehow linked by impaired automatic attention allocation processes towards high arousing emotional stimuli.

Depression and low emotional arousal also have been explained by reduced right temporo-parietal cortex function (Heller \& Nitschke, 1997). The original hypothesis of impaired right temporo-parietal cortex function in depression has been based on perceptual and visuo-spatial asymmetry measures. Heller, Etienne, \& Miller (1995) applied a face-processing task that normally evokes a left hemi-spatial bias (right hemisphere bias). Participants with high levels of depression showed a significantly reduced left hemi-spatial bias (right hemisphere bias) as compared to normal controls. The authors concluded that high levels of depression were associated with reduced right hemisphere activity. Keller et al., (2000), also found right posterior deficits in participants with high levels of depression using a perceptual asymmetry task. Therefore, given the evidence of a right fronto-parietal cortical attention system involved in directing attention towards emotional high arousing stimuli, it is likely that depressed patients fail to activate a part of this circuit. Interestingly, both studies (Heller et al., 1995; Keller et al., 2000) have found an opposite pattern in high anxious participants. High anxious subjects showed increased left hemi-spatial bias. This could be due to an overactive right fronto-parietal cortical attention circuit. Anxiety has been associated with increased vigilance and detection of fear relevant stimuli (MacNamara \& Hajcak, 2009; Öhman et al., 2001).

Cortical activation in depression also has been investigated by using resting state EEG. Thereby, it is assumed that increased alpha band activity $(8-12 \mathrm{~Hz})$ reflects reduced cortical tonal activation (Oakes et al., 2004). When controlled for anxiety symptoms, depression has been associated with increased alpha band power at right parietal electrode sites indicating less activity of right parietal cortex in these patients (Blackhart, Minnix
\& Kline, 2006; Bruder et al., 1997; Kentgen et al., 2000). High anxiety results in an opposite pattern (Bruder et al., 1997; Kentgen et al., 2000). These results have been supported by the observation that people with high family risk for depression (like first grade relatives of depressive patients) show increased cortical thinning in right temporo-parietal cortex (Peterson et al., 2009). Further, increased EEG alpha band power at right occipital electrode sites was correlated with cortical thinning in the same sample (Bruder et al., 2012).

However, all these data do not show directly that high emotional arousing stimuli do not engage properly right temporoparietal cortex in depressive patients. A more direct measure would be needed to demonstrate that part of the fronto-parietal cortical attention system does not respond (or less) to emotional stimuli in depression. Using visual steady state evoked fields recorded by MEG, Moratti et al., (2004), showed that a right fronto-parietal cortical network is engaged during an emotional picture-viewing task. In this study, high arousing pleasant, unpleasant and low arousing neutral emotional pictures were selected from the IAPS. The advantage of the IAPS picture set is that normative data with respect to valence and arousal are available. High arousing emotional stimuli evoked greater neuromagnetic oscillatory brain responses in right fronto-parietal brain regions than neutral pictures. Thus, this experimental design would be ideally suited to study depressive patients in order to test the hypothesis of reduced right temporo-parietal activity during emotional arousal as postulated by Wendy Heller (see above)

Moratti, Rubio, Campo, Keil, and Ortiz (2008) repeated the above-cited study but included a sample of patients suffering from major depressive disorder. All patients were required to have low scorings in anxiety measures, as anxiety would predict enhanced right hemisphere activity (see above). High arousing emotional pictures (pleasant and unpleasant) evoked enhanced neuromagnetic oscillatory brain activity in occipital, temporal and parietal regions in healthy controls. However, depressive patients were characterized by a weak emotional arousal modulation of right temporo-parietal cortex activity. This was the first direct evidence, that depressive patients indeed do not modulate the activity in right temporo-parietal cortex adequately as a function of emotional arousal. As the right temporo-parietal cortex can be considered as a part of the fronto-parietal cortical attention system, it can be concluded that depression probably is associated with less attentional engagement towards emotional stimuli. A good complementary test would consist in a sample of anxiety patients. In these patients an increased modulation of right parietal activity by emotional arousal would be expected (Kentgen et al., 2000).

However, it is not known if the right temporo-parietal dysfunction during emotional picture processing is a cause or an effect of depression. Therefore, it would be important to test high-risk family members of depression with the same task. Thereby, it could be tested if participants that have a high 
genetic risk for developing depression but that still have not developed depression show the same right temporo-parietal deficit or not. Given the results of cortical thinning in high risk family members of depressive patients (Peterson et al., 2009) we hypothesize that reduced emotional activity modulation in right temporo-parietal cortex would be observed in family members of depression.

If this hypothesis turned out not to be rejected, a possible precursor of depression could consist in a dysfunctional cortical fronto-parietal attention system not properly activated by emotionally relevant stimuli. This failure could explain the low emotional arousal often observed in depression. Nevertheless, it is still an open issue if this temporo-parietal deficit is specific to emotion. Depression has been characterized by deficits in executive functions such as working memory, goal directed behavior and performance of spatial tasks (for example Levin, Heller, Mohanty, Herrington \& Miller, 2007). All these domains of cognitive functioning depend on attention and its associated cortical networks. A common neuronal deficit underlying all these domains could represent an interesting candidate for an endophenotype of depression.

\section{References}

1. Amaral, D. G. (1986). Amygdalohippocampal and amygdalocortical projections in the primate brain. Advances in Experimental Medicine and Biology, 203, 3-17.

2. Amaral, D. G., Price, J. L., Pitkaenen, A., \& Carmichael, S. T. (1992). Anatomical organization of the primate amygdaloid complex. In J. P. Aggleton (Ed.), The amygdala: Neurobiological aspects of emotion, memory, and mental dysfunction (pp. 1-66). New York: Wiley-Liss.

3. Blackhart, G. C., Minnix, J. A., \& Kline, J. P. (2006). Can EEG asymmetry patterns predict future development of anxiety and depression? A preliminary study. Biological Psychology, 72, 46-50. http://dx.doi.org/10.1016/j.biopsycho.2005.06.010

4. Bradley, M. M. (2009). Natural selective attention: Orienting and emotion. Psychophysiology, 46, 1-11. http://dx.doi. org/10.1111/j.1469-8986.2008.00702.x

5. Bradley, M. M., Codispoti, M., Cuthbert, B. N., \& Lang, P. J. (2001). Emotion and Motivation I: Defensive and Appetitive Reactions in Picture Processing. Emotion, 1, 276-298. http://dx.doi.org/10.1037/1528-3542.1.3.276

6. Bradley, M. M., Lang, P. J., \& Cuthbert, B. N. (1993). Emotion, novelty, and the startle reflex: habituation in humans. Behavioral Neuroscience, 107, 970-980. http://dx.doi. org/10.1037/0735-7044.107.6.970

7. Bruder, G. E., Bansal, R., Tenke, C. E., Liu, J., Hao, X., Warner, V., et al. (2012). Relationship of resting EEG with anatomical MRI measures in individuals at high and low risk for depression. Human Brain Mapping, 33, 1325-1333. http://dx.doi.org/10.1002/hbm.21284

8. Bruder, G. E., Fong, R., Tenke, C. E., Leite, P., Towey, J.
P., Stewart, J. E., et al. (1997). Regional brain asymmetries in major depression with or without an anxiety disorder: a quantitative electroencephalographic study. Biological Psychiatry, 41, 939-948. http://dx.doi.org/10.1016/S00063223(96)00260-0

9. Chelazzi, L., Duncan, J., Miller, E. K., \& Desimone, R. (1998). Responses of neurons in inferior temporal cortex during memory-guided visual search. Journal of Neurophysiology, 80, 2918-2940.

10. Codispoti, M., Ferrari, V., \& Bradley, M. M. (2006). Repetitive picture processing: autonomic and cortical correlates. Brain Research, 1068, 213-220. http://dx.doi.org/10.1016/j. brainres.2005.11.009

11. Critchley, H. D. (2002). Electrodermal responses: what happens in the brain. The Neuroscientist, 8, 132-142. http:// dx.doi.org/10.1177/107385840200800209

12. Cuthbert, B. N., Schupp, H. T., Bradley, M. M., Birbaumer, N., \& Lang, P. J. (2000). Brain potentials in affective picture processing: covariation with autonomic arousal and affective report. Biological Psychology, 52, 95-111. http://dx.doi.org/10.1016/S0301-0511(99)00044-7

13. Driver, J., \& Vuilleumier, P. (2001). Perceptual awareness and its loss in unilateral neglect and extinction. Cognition, 79, 39-88. http://dx.doi.org/10.1016/S00100277(00)00124-4

14. Forbes, E. E., Miller, A., Cohn, J. F., Fox, N. A., \& Kovacs, M. (2005). Affect-modulated startle in adults with childhood-onset depression: relations to bipolar course and number of lifetime depressive episodes. Psychiatry Research, 134, 11-25. http://dx.doi.org/10.1016/j.psychres.2005.01.001

15. Gehricke, J., \& Shapiro, D. (2000). Reduced facial expression and social context in major depression: discrepancies between facial muscle activity and self-reported emotion. Psychiatry Research, 95, 157-167. http://dx.doi. org/10.1016/S0165-1781(00)00168-2

16. Grandjean, D., Sander, D., Pourtois, G., Schwartz, S., Seghier, M. L., Scherer, K. R., et al. (2005). The voices of wrath: brain responses to angry prosody in meaningless speech. Nature Neuroscience, 8, 145-146. http://dx.doi. org/10.1038/nn1392

17. Hajcak, G., Dunning, J. P., \& Foti, D. (2009). Motivated and controlled attention to emotion: time-course of the late positive potential. Clinical Neurophysiology, 120, 505-510. http://dx.doi.org/10.1016/j.clinph.2008.11.028

18. Heller, W., Etienne, M. A., \& Miller, G. A. (1995). Patterns of perceptual asymmetry in depression and anxiety: implications for neuropsychological models of emotion and psychopathology. Journal of Abnormal Psychology, 104, 327333. http://dx.doi.org/10.1037/0021-843X.104.2.327

19. Heller, W., \& Nitschke, J. B. (1997). Regional brain activity in emotion: A framework for understanding cognition in depression. Cognition and Emotion, 11, 637-661. http:// 
dx.doi.org/10.1080/026999397379845a

20. Heller, W., Nitschke, J. B., \& Lindsay, D. L. (1997). Neuropsychological Correlates of Arousal in Self-reported Emotion. Cognition and Emotion, 11, 383-402. http://dx.doi. org/10.1080/026999397379854

21. Heller, W., Nitschke, J. B., \& Miller, G. A. (1998). Lateralization in Emotion and Emotional Disorders. Current Directions in Psychological Science, 7, 26-32. http:// dx.doi.org/10.1111/1467-8721.ep11521823

22. Kanwisher, N., \& Yovel, G. (2006). The fusiform face area: a cortical region specialized for the perception of faces. Philosophical Transactions of the Royal Society B: Biological Sciences, 361, 2109-2128. http://dx.doi.org/10.1098/ rstb.2006.1934

23. Keil, A., Moratti, S., Sabatinelli, D., Bradley, M. M., \& Lang, P. J. (2005). Additive effects of emotional content and spatial selective attention on electrocortical facilitation. Cerebral Cortex, 15, 1187-1197. http://dx.doi.org/10.1093/ cercor/bhi001

24. Keil, A., Stolarova, M., Moratti, S., \& Ray, W. J. (2007). Adaptation in human visual cortex as a mechanism for rapid discrimination of aversive stimuli. Neuroimage, 36, 472479. http://dx.doi.org/10.1016/j.neuroimage.2007.02.048

25. Keller, J., Nitschke, J. B., Bhargava, T., Deldin, P. J., Gergen, J. A., Miller, G. A., et al. (2000). Neuropsychological differentiation of depression and anxiety. Journal Abnormal Psychology, 109, 3-10. http://dx.doi.org/10.1037/0021$\underline{843 X} .109 .1 .3$

26. Kentgen, L. M., Tenke, C. E., Pine, D. S., Fong, R., Klein, R. G., \& Bruder, G. E. (2000). Electroencephalographic asymmetries in adolescents with major depression: influence of comorbidity with anxiety disorders. Journal of Abnormal Psychology, 109, 797-802. http://dx.doi.org/10.1037/0021843X.109.4.797

27. Lang, P. J., Bradley, M. M., \& Cuthbert, B. N. (1997). Motivated Attention: Affect, Activation, and Action. In P. J. Lang, R. F. Simons \& M. T. Balaban (Eds.), Attention and Orienting: Sensory and Motivational Processes (pp. 97-135). Hillsdale, N.J.: Lawrence Erlbaum Associates.

28. Lang, P. J., Bradley, M. M., \& Cuthbert, B. N. (2005). International affective picture system (IAPS): Affective ratings of pictures and instruction manual. Technical Report A-6. Gainesville, FL: University of Florida.

29. Lang, P. J., \& Davis, M. (2006). Chapter 1 Emotion, motivation, and the brain: Reflex foundations in animal and human research. Progress in Brain Research, 156, 3-29. http://dx.doi.org/10.1016/S0079-6123(06)56001-7

30. LeDoux, J. E. (1993). Emotional networks in the brain. In J. M. H. Michael Lewis (Ed.), Handbook of emotions (pp. 109-118), New York: Guilford Press.

31. LeDoux, J. E. (2000). Emotion circuits in the brain. Annual Review of Neuroscience, 23, 155-184. http://dx.doi. org/10.1146/annurev.neuro.23.1.155
32. Levin, R. L., Heller, W., Mohanty, A., Herrington, J. D., \& Miller, G. A. (2007). Cognitive deficits in depression and functional specificty of regional brain activity. In R. Atchley \& S. Ilardi (Eds.), Cognitive Neuroscience Perspectives on Depression, Special Issue. Cognitive Therapy and Research, 31, 211-233.

33. MacNamara, A., \& Hajcak, G. (2009). Anxiety and spatial attention moderate the electrocortical response to aversive pictures. Neuropsychologia, 47, 2975-2980. http://dx.doi. org/10.1016/j.neuropsychologia.2009.06.026

34. Meadows, M. E., \& Kaplan, R. F. (1994). Dissociation of autonomic and subjective responses to emotional slides in right hemisphere damaged patients. Neuropsychologia, 32, 847-856. http://dx.doi.org/10.1016/0028-3932(94)90022-1

35. Moratti, S., Clementz, B. A., Gao, Y., Ortiz, T., \& Keil, A. (2007). Neural mechanisms of evoked oscillations: Stability and interaction with transient events. Human Brain Mapping, 28, 1318-1333. http://dx.doi.org/10.1002/hbm.20342

36. Moratti, S., \& Keil, A. (2009). Not what you expect: experience but not expectancy predicts conditioned responses in human visual and supplementary cortex. Cerebral Cortex, 19, 2803-2809. http://dx.doi.org/10.1093/cercor/bhp052

37. Moratti, S., Keil, A., \& Stolarova, M. (2004). Motivated attention in emotional picture processing is reflected by activity modulation in cortical attention networks. Neuroimage, 21, 954-964. http://dx.doi.org/10.1016/j.neuroimage.2003.10.030

38. Moratti, S., Rubio, G., Campo, P., Keil, A., \& Ortiz, T. (2008). Hypofunction of right temporoparietal cortex during emotional arousal in depression. Archives of General Psychiatry, 65, 532-541. http://dx.doi.org/10.1001/ archpsyc.65.5.532

39. Moratti, S., Saugar, C., \& Strange, B. A. (2011). Prefrontal-occipitoparietal coupling underlies late latency human neuronal responses to emotion. Journal of Neuroscience, $31, \quad 17278-17286$. http://dx.doi.org/10.1523/JNEUROSCI.2917-11.2011

40. Morgan, S. T., Hansen, J. C., \& Hillyard, S. A. (1996). Selective attention to stimulus location modulates the steady-state visual evoked potential. Proceeding of the National Academy of Science U S A, 93, 4770-4774. http:// dx.doi.org/10.1073/pnas.93.10.4770

41. Muller, M. M., Andersen, S., Trujillo, N. J., Valdes-Sosa, P., Malinowski, P., \& Hillyard, S. A. (2006). Feature-selective attention enhances color signals in early visual areas of the human brain. Proceedings of the National Academy of Science US A, 103, 14250-14254. http://dx.doi.org/10.1073/ pnas.0606668103

42. Müller, M. M., \& Hillyard, S. (2000). Concurrent recording of steady-state and transient event-related potentials as indices of visual-spatial selective attention. Clinical Neurophysiology, 111, 1544-1552. http://dx.doi.org/10.1016/ $\underline{\mathrm{S} 1388-2457(00) 00371-0}$ 
43. Muller, M. M., \& Hubner, R. (2002). Can the spotlight of attention be shaped like a doughnut? Evidence from steadystate visual evoked potentials. Psychologial Science, 13, 119-124. http://dx.doi.org/10.1111/1467-9280.00422

44. Oakes, T. R., Pizzagalli, D. A., Hendrick, A. M., Horras, K. A., Larson, C. L., Abercrombie, H. C., et al. (2004). Functional coupling of simultaneous electrical and metabolic activity in the human brain. Human Brain Mapping, 21, 257-270. http://dx.doi.org/10.1002/hbm.20004

45. Ohman, A., Carlsson, K., Lundqvist, D., \& Ingvar, M. (2007). On the unconscious subcortical origin of human fear. Physiology \& Behavior, 92, 180-185. http://dx.doi. org/10.1016/j.physbeh.2007.05.057

46. Öhman, A., Flykt, A., \& Esteves, F. (2001). Emotion drives attention: detecting the snake in the grass. Journal of Experimental Psychology. General, 130, 466-478. http:// dx.doi.org/10.1037/0096-3445.130.3.466

47. Peterson, B. S., Warner, V., Bansal, R., Zhu, H., Hao, X., Liu, J., et al. (2009). Cortical thinning in persons at increased familial risk for major depression. Proceedings of the National Academy of Science U S A, 106, 6273-6278. http://dx.doi.org/10.1073/pnas.0805311106

48. Schupp, H. T., Cuthbert, B. N., Bradley, M. M., Cacioppo, J. T., Ito, T., \& Lang, P. J. (2000). Affective picture processing: the late positive potential is modulated by motivational relevance. Psychophysiology, 37, 257-261. http://dx.doi. org/10.1111/1469-8986.3720257

49. Shi, C., \& Davis, M. (2001). Visual pathways involved in fear conditioning measured with fear-potentiated startle: behavioral and anatomic studies. Journal of Neuroscience, 21, 9844-9855.
50. Shimoda, K., \& Robinson, R. G. (1999). The relationship between poststroke depression and lesion location in longterm follow-up. Biological Psychiatry, 45, 187-192. http:// dx.doi.org/10.1016/S0006-3223(98)00178-4

51. Slagter, H. A., Giesbrecht, B., Kok, A., Weissman, D. H., Kenemans, J. L., Woldorff, M. G., et al. (2007). fMRI evidence for both generalized and specialized components of attentional control. Brain Research, 1177, 90-102. http:// dx.doi.org/10.1016/j.brainres.2007.07.097

52. Sugase, Y., Yamane, S., Ueno, S., \& Kawano, K. (1999). Global and fine information coded by single neurons in the temporal visual cortex. Nature, 400, 869-873. http://dx.doi. org/10.1038/23703

53. Venables, P. H., \& Cristie, M. J. (1980). Electrodermal Activity. In I. Martin \& P. H. Venables (Eds.), Techniques in Psychophysiology (pp. 4-67). New York: Wiley.

54. Vuilleumier, P., Armony, J. L., Driver, J., \& Dolan, R. J. (2001). Effects of attention and emotion on face processing in the human brain: an event-related fMRI study. Neuron, 30, 829-841. http://dx.doi.org/10.1016/S0896$\underline{6273(01) 00328-2}$

Received 3 April 2012

Received in revised form 7 June 2012

Accepted 11 June 2012 